\title{
OREVER
}

\section{"Estuda, porque na vida de agricultor não aparecem oportunidades" - Educação e mobilidade socioespacial de jovens rurais em Minas Gerais $^{1}$}

\section{"You must study because there are no opportunities in a farmer's life" - Education and socio-spatial mobility of rural youngsters in Minas Gerais}

\author{
Sheila Maria Doula \\ sheiladoula@gmail.com

\section{Isadora Moreira Ribeiro} \\ isadora.moreiraribeiro@gmail.com
}

Universidade Federal de Viçosa. Departamento de Economia Rural. Programa de Pósgraduação em Extensão Rural. Bolsista do CNPq.

Doutoranda pelo Programa de Pós-graduação em Extensão Rural, Departamento de Economia Rural, Universidade Federal de Viçosa (PPGER/UFV).

\section{João Paulo Louzada Vieira}

joaopaulo.direito@yahoo.com.br

Mestrando do Programa de Pós-graduação em Extensão Rural, Departamento de Economia Rural, Universidade Federal de Viçosa (PPGER/UFV).

\section{Marco Paulo Andrade}

andrade.marcop@gmail.com

Mestrando do Programa de Pós-graduação em Extensão Rural, Departamento de Economia Rural, Universidade Federal de Viçosa (PPGER/UFV).

\section{Jeferson Henrique dos Reis Lopes}

jeferson.h.lopes@gmail.com

Graduando em Cooperativismo da Universidade Federal de Viçosa (UFV).

\footnotetext{
${ }^{1}$ Projeto de pesquisa "Lugares de saída, lugares de chegada: caminhos e reconfigurações simbólicas da mobilidade socioespacial entre jovens rurais da Zona da Mata Mineira", financiado pela Fundação de Amparo à Pesquisa do Estado de Minas Gerais-FAPEMIG.
}

Recebido em: 22/05/2019

Aprovado em: 21/06/2019
Revista do Programa de Pós-Graduação em Extensão Rural (UFV)

ISNN 2359-5116 | V. 8 | N.1 | JAN.-JUN. 2019 


\title{
OREVER
}

\section{RESUMO}

O artigo aborda as dificuldades de acesso ao ensino superior enfrentadas por jovens rurais, principalmente quanto à necessidade de deslocamentos espaciais. Com esse propósito, foram analisadas as informações oferecidas por jovens que constituem, no âmbito familiar, uma geração pioneira de universitários. A metodologia consistiu em aplicação de questionários a jovens rurais universitários da Zona da Mata de Minas Gerais. Entre os resultados, destaca-se a influência do capital de migração criado pelas trajetórias familiares na concretização desse projeto e na elaboração de projetos futuros de vida.

Palavras-Chave: Juventude Rural; Educação Superior; Deslocamentos Espaciais; Projetos de Vida.

\begin{abstract}
This article studies the obstacles faced by rural youth in accessing college education, mainly by the need of spatial displacement. To this end, we analyzed the information provided by rural youngsters who became the pioneer generation of college-educated members in their families. The methodology of this research consisted of questionnaire application among rural college students in the region of Zona da Mata in Minas Gerais. Among the results, it is possible to highlight the influence of the migration capital built by the previous generations on the fulfillment of the educational plan and on the construction of future life projects.
\end{abstract}

Keywords: Rural Youth; College Education; Spatial Displacement; Life Projects. 


\section{OREVER}

\section{Introdução}

Pesquisas recentes têm demonstrado que o acesso à educação representa, ainda hoje, fator de desigualdade social e demanda política da juventude rural em várias partes do mundo. Apesar da expansão do número de estabelecimentos de ensino de níveis médio e superior e da implementação de políticas públicas inclusivas nas duas últimas décadas em diferentes países, o acesso à educação implica para a juventude rural velhos e novos dilemas de ordem econômica, cultural e subjetiva. Os deslocamentos espaciais rumo às cidades, que permanecem como condicionantes para a concretização desse projeto, pressupõem, em primeiro lugar, investimentos econômicos familiares, que, na maioria das vezes, são vistos como sacrifício; em segundo lugar, é necessário um cálculo da sobrecarga para outros membros na divisão familiar do trabalho enquanto os jovens estudam; e finalmente, há o desafio das reformulações nos projetos familiares de afirmação ou negação de sua reprodução social como agricultores, pois não há certeza de que jovens mais escolarizados retornem ao trabalho na agricultura ou à propriedade familiar.

Alguns exemplos bastam para mapear cenários e restrições para a concretização do projeto de maior escolaridade, que é ao mesmo tempo individual e familiar. Na China, mesmo com a expansão recente de programas governamentais de acesso à educação, a migração rural-urbana se impõe nos cálculos das famílias rurais como condicionante para que os filhos permaneçam na escola e alcancem níveis médios e superiores de escolaridade. Chiang, Hannum e Kao (2012) mostram que, além da necessidade do deslocamento, esses cálculos são balizados por aspectos culturais tradicionais relativos à valorização diferenciada dos gêneros e à posição hierárquica entre irmãos, o que torna a educação uma oportunidade desigual e até mesmo competitiva no âmbito da própria família. A preferência por filhos homens e a prioridade dos mais jovens sobre os mais velhos são valores culturais que limitam, por um lado, as possibilidades de irmãos mais velhos continuarem sua trajetória educacional, pois irão trabalhar nas propriedades rurais para prover os familiares, e por outro, as oportunidades das filhas, geralmente mais velhas, que são motivadas a migrar para as cidades para trabalhar e pagar as despesas educacionais dos irmãos mais novos. Destaca-se que, além do aspecto cultural, as famílias de pequenos produtores rurais chineses vivem em condições socioeconômicas de pobreza, o que também influencia, de forma seletiva, as estratégias e decisões familiares sobre quem migra para o trabalho e quem migra para o estudo. 


\section{OREVER/|}

Em perspectiva diferente, Irvin et al. (2012) analisam as variáveis que interferem nas aspirações de acesso ao ensino superior de jovens rurais de origem afro e latinoamericana que frequentam escolas secundárias rurais nos Estados Unidos. Para os autores, as aspirações profissionais e sociais desses alunos são mais limitadas e percebidas pelos próprios jovens como resultado de contextos rurais de pobreza, discriminação étnica e desvalorização social das atividades realizadas no campo. Os próprios jovens argumentam que os tipos de trabalho que fornecem a maioria dos empregos nos espaços rurais não requerem educação pós-secundária, e o fato de trabalharem desde cedo nas tarefas agrícolas cotidianas se configura uma barreira para a continuidade dos estudos, bem como reforça as clivagens para a mobilidade social em uma sociedade competitiva. Além da dificuldade econômica familiar para custear os jovens longe de casa para estudar, a ausência de antecedentes migratórios para fins de estudo nas gerações anteriores são fatores que, segundo os autores, contribuem para tornar a pobreza rural duradoura e intergeracional.

Conclusões semelhantes são apontadas na pesquisa de Leavy e Smith (2010) sobre o contexto agrário de países da África subsaariana. As autoras analisam a defasagem entre a aspiração e a realização das expectativas dos jovens rurais, destacando que, embora esses jovens almejem "melhorar de vida", as opções para a mobilidade social ascendente são atualmente limitadas: poucos têm um nível de educação suficiente para uma carreira profissional fora da agricultura, as economias urbanas declinam devido a guerras civis e as famílias rurais não dispõem de recursos econômicos suficientes para arcar com a migração juvenil como forma de viabilizar a educação. Leavy e Smith (2010) ressaltam que, em áreas rurais estagnadas e empobrecidas, não há diversidade de modelos profissionais que inspirem projetos de vida juvenis diferenciados ou transformadores, daí as escolhas serem restritivas, repetindo o próprio modelo familiar. As autoras concluem que, nesses projetos profissionais, transparecem pressões socioculturais que ora valorizam a maior escolaridade como sinônimo de ascensão social, ora encorajam o conformismo e a desconfiança em se aventurar em novas experiências e modelos.

A pesquisa de Crivello (2009), referindo-se ao contexto latino-americano, constata que a educação, notadamente a de nível universitário, tem adquirido relevância nos processos de globalização como valor simbólico para gerar uma "juventude bemsucedida". No Peru, lócus de sua pesquisa, a incorporação social desse valor pelas famílias rurais faz com que as aspirações educacionais e profissionais estejam mais elevadas e diversificadas que nas gerações anteriores. Embora essas aspirações sejam 


\section{OREVER/|}

produzidas em um contexto de enormes desigualdades econômicas e sociais, e em meio a histórias recentes de violência política e deslocamentos populacionais em massa, os jovens rurais e seus pais atribuem à educação, principalmente a de nível superior, o papel privilegiado no projeto de "se tornar alguém na vida", e nele reside a principal esperança de se romper a transmissão intergeracional da pobreza e da marginalização. Visto como projeto de ascensão social, ao mesmo tempo individual e familiar, o acesso a níveis superiores de educação pressupõe como condicionante a migração dos filhos e, por vezes, de toda a família para os centros urbanos. Aliás, "tornar-se alguém na vida", para os jovens rurais, implica tornar-se alguém “em algum outro lugar” (CRIVELLO, 2009).

Estudos realizados no Brasil confirmam algumas conclusões gerais apresentadas por essas pesquisas internacionais. Tal como em outros países, aqui também se verificou, na década de 1990, o crescimento do número de estabelecimentos de ensino superior, embora esse processo tenha sido marcado inicialmente por projetos políticos de privatização do ensino. No caso brasileiro, políticas criadas pelo governo Lula, a partir de 2003, reorientaram os investimentos para o setor público, dando início ao processo conhecido como "interiorização" do ensino superior, norteado pelo Programa de Apoio a Planos de Reestruturação e Expansão das Universidades Federais (REUNI). Se observarmos dados fornecidos pelo Instituto Nacional de Estudos e Pesquisas Educacionais Anísio Teixeira (INEP), em 2001, o país contava com 1.391 instituições de ensino superior, sendo 183 públicas (65 localizadas nas capitais e 118 em cidades do interior) e 1.208 particulares (445 nas capitais e 763 nas cidades do interior). Já em 2015, haviam 2.407 estabelecimentos, dos quais 296 públicos (98 situados nas capitais e 198 no interior) e 2.111 privados, estando 766 situados nas capitais e 1.345 em cidades do interior (INEP, 2002 e 2016).

Apesar da maior oferta de estabelecimentos públicos e privados de ensino superior nas cidades do interior e da implementação de políticas inclusivas de acesso (como o sistema de cotas sociais criado no âmbito do Programa Universidade para TodosPROUNI e o Fundo de Financiamento Estudantil-FIES), pode-se considerar que a educação, em todos os níveis, ainda se constitui como uma demanda da juventude rural brasileira (STROPASOLAS, 2014). Dados de 2009, coletados pelo Departamento Intersindical de Estatística e Estudos Socioeconômicos (DIEESE), ao compararem os níveis de escolaridade, mostram algumas persistências dessas desigualdades: $20 \%$ da população urbana possui ensino médio completo, contra $8 \%$ da rural; $3,9 \%$ da população urbana possui superior incompleto, enquanto no meio rural, apenas $0,8 \% ; 7,6 \%$ da 


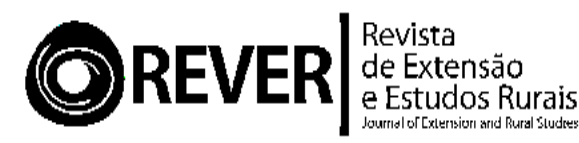

população urbana possui superior completo e apenas $1,2 \%$ da rural atingem esse nível (ZAGO; 2016, p. 64).

Zago destaca que "o prolongamento da escolarização para além do ensino fundamental é relativamente recente entre os filhos de agricultores" (ZAGO; 2016, p. 64). De fato, pesquisadores brasileiros que focalizaram a juventude rural nas duas últimas décadas apontaram que o acesso ao ensino superior está cada vez mais se incorporando nos projetos profissionais dos jovens, com diferentes campos de possibilidade de concretização. Assim como verificado em outros contextos internacionais, no Brasil, a educação também vem sendo identificada pelas famílias rurais como condição para o jovem "ser alguém na vida" (CARNEIRO, 2005) e para ocupar um lugar "digno" na sociedade em geral (STROPASOLAS, 2014). "Ficar ou sair" do campo passa a ser uma decisão norteada não apenas em função da procura por trabalho urbano, mas também pela busca de educação prolongada e seu significado subjetivo de reconhecimento social e dignidade. Os pesquisadores acentuaram que, para os jovens rurais brasileiros, a perspectiva de um padrão de vida melhor inclui no projeto de vida o percurso migratório, ainda que temporário, o que é ponderado não apenas pelas condições socioeconômicas das famílias, mas principalmente pelo sentimento de compromisso com o trabalho familiar, com a comunidade e com o local, sendo esse o cálculo mais difícil para alcançar "o melhor dos dois mundos", o rural e o urbano (ABRAMOVAY et al., 2007; CASTRO, 2009; CARNEIRO, 1999).

Se o acesso de jovens rurais ao ensino superior estava bem delineado nas pesquisas acadêmicas como demanda política e projeto de vida futuro, pode-se dizer que há atualmente uma agenda de investigação em aberto que diz respeito à concretização de tal projeto por parte da juventude rural e às condições internas e externas às famílias que permitiram viabilizá-lo. Entre as pautas importantes dessa agenda a serem verificadas, se encontram: o resultado das políticas públicas de interiorização do ensino superior e as oportunidades de acesso de jovens rurais, as trajetórias universitárias, o perfil dos egressos e também as novas estratégias e investimentos das famílias rurais que reorientam, semanticamente, os sentidos da expressão "ser alguém na vida".

Pesquisas recentes e delineadas como estudo de caso têm apontado algumas pistas importantes que podem se firmar como novos eixos investigativos. Em estudo realizado com jovens rurais universitários do oeste de Santa Catarina, por exemplo, Zago (2016) constatou algumas mudanças que vêm se processando no âmbito familiar, diferenciando as gerações quanto ao incentivo à migração com finalidade educacional. Diferentemente 


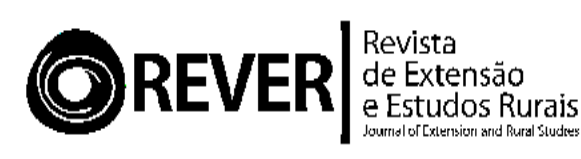

do passado, hoje o projeto familiar já não se restringe à escolha de um dos filhos para "prosseguir os estudos, permanecendo os demais na agricultura", o que significa que a oportunidade de prolongamento e permanência no sistema de ensino pode ser igualmente concedida "independentemente do sexo e da posição na fratria” (ZAGO; 2016, p. 76).

Zago destaca que, além do âmbito familiar, essas transformações também nos convidam a repensar o êxodo rural juvenil sob dois aspectos. O primeiro indica que o aumento de capital escolar pode representar uma ruptura com a continuidade de reprodução social das famílias de agricultores e do trabalho no campo, posto que os jovens e seus familiares elaboram representações negativas sobre a degradação social, a desvalorização simbólica e as condições de trabalho restritivas que se colocam como obstáculos à sobrevivência da agricultura familiar, daí crescer o incentivo da família para que os jovens consigam ocupações urbanas e permaneçam nas cidades. Em segundo lugar, também não se pode deixar de considerar que a própria experiência da convivência urbana durante a fase dos estudos resulta em "novas experiências sociais e culturais, podendo ampliar o campo de interesse para outros horizontes de possibilidades" (ZAGO, 2016, p. 76), o que vem sendo apresentado com positividade pelas famílias, dado que os jovens se apropriam de modelos profissionais mais diversificados e valorizados socialmente. Assim, o acesso ao ensino superior parece configurar também, para as famílias rurais, uma nova forma de viver a juventude, de obter autonomia e de adentrar o mundo adulto.

Entretanto, o deslocamento para as cidades para a continuidade dos estudos não resulta, automaticamente, em uma unanimidade nos projetos juvenis de permanência definitiva no meio urbano (ZAGO; 2016). Ao contrário, o retorno ao meio rural ainda está presente nos projetos de vida dessa juventude mais escolarizada, como indicam pesquisas realizadas em Serra Talhada, em Pernambuco (DE PAULO e SILVA, 2013), e em Araquém, no estado do Ceará (BEZERRA, 2013). Um fato comum identificado nessas pesquisas refere-se ao movimento pendular, ou seja, ao deslocamento diário das zonas rurais para as cidades para cursar a faculdade. Bezerra utiliza o termo "universitários-viajantes" como categoria identitária utilizada pelos próprios jovens e destaca que, para eles, "ir sabendo que se pode voltar para dormir em casa (...) alimenta as perspectivas de permanecer no local de origem"; o que não significa que estão satisfeitos com as condições locais, mas que, ao contrário, o maior capital escolar faz com que se considerem "agentes de transformação" (BEZERRA, 2013, p. 131). Ficar no meio rural após a faculdade não significaria fracasso, pois “esses jovens optam por transformar 


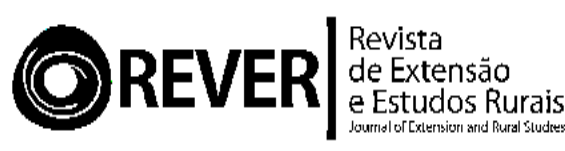

o rural habitado em um lugar que atenda às suas expectativas de 'ficar', mas ficar de uma forma diferente" (BEZERRA, 2013, p. 133). De Paulo e Silva também concluem, em sua pesquisa realizada em Pernambuco, que os jovens rurais universitários entrevistados projetam "voltar para o seu meio ou ficar em sua região e contribuir para o seu desenvolvimento. Percebem alguma oportunidade e querem construir outras" (DE PAULO e SILVA, 2013, p. 8).

Os resultados dessas pesquisas, ainda que tímidos, permitem apontar que há reconfigurações simbólicas em curso e que também há um novo leque de opções para as famílias rurais quanto ao projeto de sua reprodução social, à construção da autonomia juvenil e aos caminhos da mobilidade social. Considerando essas modificações, pretendese, neste artigo, analisar dados parciais de uma investigação sobre diferentes trajetórias socioespaciais de famílias rurais na contemporaneidade, enfatizando-se, aqui, a elaboração de projetos de vida de jovens rurais universitários. $\mathrm{Na}$ análise dos dados, a utilização dos conceitos de capital de mobilidade (RYE, 2011) e de projetos de vida (VELHO, 2004; ALVES e DAYRELL, 2015) pretende indicar, de forma exploratória, que resultados positivos dos deslocamentos espaciais de membros das famílias podem criar um habitus migratório (DE OLIVEIRA e KULAITIS, 2017) que influencia os projetos de vida das gerações mais novas, auxiliando a concretização, no presente, de projetos de maior escolaridade e de projetos futuros em outros lugares.

\section{Metodologia e lócus da pesquisa}

A pesquisa foi desenvolvida com jovens rurais universitários da Zona da Mata de Minas Gerais. A região, como mostra a bibliografia, apresenta historicamente movimentos populacionais diversos, em diferentes épocas e com sentidos geográficos distintos, orientados por várias motivações. Comerford (2014) utilizou as categorias nativas "andanças" e "perambulações" para indicar que, na região, os deslocamentos espaciais não são representados como excepcionalidade, mas sim como fluxos contínuos e corriqueiros. "Não há família na zona rural da Zona da Mata mineira”, segundo o autor, "que não tenha histórias para contar sobre idas e vindas, próprias e alheias, recentes ou antigas, para os grandes centros ou cidades industriais do Sudeste" (COMERFORD, 2014, p. 120). Tais deslocamentos fornecem narrativas sobre sucessos e fracassos, permanências e retornos, permeadas "de considerações sobre trabalho, sofrimento, coragem e vitórias, sobre dificuldades, aventuras" (Idem, p. 129). Deslocar-se é, portanto, 


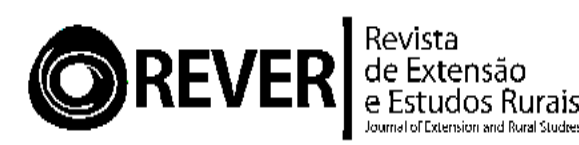

um dado cultural, ou, expressando de outra forma, um habitus das famílias rurais da região.

$\mathrm{Na}$ pesquisa aqui descrita, foram aplicados 45 questionários semiestruturados, focalizando os temas da migração, do trabalho e das oportunidades educacionais. Além de respostas a questões abertas, foi solicitado aos jovens o preenchimento de um quadro com as trajetórias migratórias dos familiares, motivos dos deslocamentos e períodos de permanência em cada lugar de destino. Essa amostra é composta por jovens rurais que se encontram em deslocamento espacial devido aos estudos universitários, e todos são discentes da Universidade Federal de Viçosa, localizada na Zona da Mata de Minas Gerais.

A cidade de Viçosa é reconhecida como polo educacional da região e a Universidade Federal de Viçosa, inaugurada em 1926, foi criada obedecendo o modelo dos land-grant college norte-americanos, visando à educação agronômica dos filhos de fazendeiros (RIBEIRO, 2006). Embora a identidade institucional da UFV tenha sido construída pelas Ciências Agrárias, atualmente a universidade conta com 67 cursos de graduação em todas as áreas do conhecimento, oferecidos em três campi, em diferentes cidades do interior de Minas Gerais.

Para participar da pesquisa, o critério de seleção da amostra foi a autodefinição de origem rural. A média da faixa etária dos entrevistados é de 22,4 anos, sendo $45 \%$ do sexo feminino e 55\% do sexo masculino. Os universitários estão matriculados em cursos de diferentes áreas do conhecimento no campus da UFV da cidade de Viçosa.

\section{Análise e discussão dos dados}

Algumas informações sobre as trajetórias dos jovens participantes da pesquisa são pertinentes para a melhor compreensão de seus projetos de vida na atualidade e na nova condição de universitários. Os entrevistados são nascidos na mesorregião da Zona da Mata de Minas Gerais, e foi verificado que, ao longo de suas trajetórias, realizaram alguns deslocamentos para as cidades (Viçosa e outras da região), com a finalidade de cursarem o ensino médio e o ensino superior. $\mathrm{Na}$ amostra, constata-se que esses jovens constituem a primeira geração da família a alcançar o nível superior de ensino, confirmando um pioneirismo geracional já destacado nas pesquisas de De Paulo e Silva (2013) e Bezerra (2013).

Enquanto os jovens estão estudando, as propriedades rurais ficam a cargo somente dos pais (em 36 casos), dos pais e avós (3 casos), dos pais e irmãos mais velhos (5 casos) 


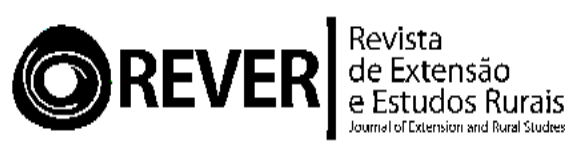

e dos funcionários (1 caso). Tal configuração familiar também foi encontrada por Zago (2016) em Santa Catarina, onde apenas as pessoas mais velhas mantêm o funcionamento da propriedade, enquanto os filhos estão fora para estudar. Zago considera que essa ausência, mesmo que temporária, dos jovens não só aponta dificuldades futuras nos processos sucessórios, mas também afeta a gestão das propriedades rurais no presente devido à sobrecarga de trabalho para os demais membros das famílias. No entanto, apesar dessa configuração semelhante, os jovens rurais participantes da pesquisa afirmam que as propriedades familiares permanecem produtivas e com retorno econômico, derivado de atividades agrícolas e pecuárias, e da administração de pousadas e lanchonetes; somente 5 jovens apontaram que a propriedade atualmente não produz "nada" ou produz “apenas para subsistência”.

Dado relevante da pesquisa refere-se aos deslocamentos espaciais identificados nas narrativas sobre as trajetórias familiares dos jovens participantes, que descreveram um emaranhado de idas e vindas de diferentes gerações e de familiares com diversos graus de parentesco, confirmando a assertiva da migração como elemento cultural da região (COMERFORD, 2014). Tal constatação também nos põe a caminho de analisar essas trajetórias a partir do conceito de capital de mobilidade, inspirado na teoria do habitus e de capitais, formulada por Pierre Bourdieu (1974, 2007). Embora fatores econômicos de expulsão ou de atração populacional permaneçam importantes para estudos migratórios, propõe-se também considerar o campo de possibilidades para a concretização de aspirações diversas, de ordem não estritamente econômica, e as valorizações positivas dos resultados dos deslocamentos, que são transmitidas socialmente e que retroalimentam o habitus migratório. Assim, define-se o conceito de capital de mobilidade como as predisposições e os esquemas de ação que fornecem familiaridade com a mobilidade no espaço em vários níveis, orientando as representações e as práticas dos indivíduos (RYE, 2011; DE OLIVEIRA e KULAITIS, 2017; BRITO, 2010).

Todos os 45 jovens mapearam processos migratórios familiares tanto nas gerações de seus avós (aqui chamada de primeira geração) e de pais e tios (segunda geração), quanto na própria (terceira geração). Onze jovens forneceram informações sobre avós paternos ou maternos migrantes, compondo um grupo de 23 pessoas da primeira geração, entre as quais 12 realizaram deslocamento rural-urbano e 11 realizaram deslocamento rural-rural. Para os dois tipos de deslocamento, o principal motivo apresentado foi a oportunidade de trabalho em outro lugar, principalmente em outros estados da região Sudeste. 


\section{OREVER}

Entre os jovens, 32 apontaram migrantes na segunda geração: 16 indicaram tios e 20 citaram os pais, perfazendo um total de 91 membros familiares que migraram. A migração rural-urbana prevaleceu, sendo a principal motivação a procura de trabalho, seguida pelo casamento. Constatou-se que entre as 91 pessoas da segunda geração que migraram, 47 retornaram ao meio rural, retomando as atividades agropecuárias das propriedades familiares ou adquirindo novas terras.

Considerando a geração dos jovens entrevistados, composta também por irmãos e primos, 25 declararam ter irmãos e 8 declararam ter primos, de ambos os sexos, realizando deslocamento por motivo de estudo, superior ou secundário. Os jovens participantes da pesquisa consideram que a migração em razão do trabalho era a única alternativa de mobilidade social para as gerações anteriores. Como são jovens universitários, o fato de poderem cursar uma universidade e terem essa oportunidade disponibilizada na própria região cria uma diferença geracional importante. Para os entrevistados, o estudo é a principal motivação para o deslocamento de sua geração, pois, além deles próprios, incluise porcentagem significativa de irmãos(ãs) e primos(as) nessa condição, havendo inclusive três indivíduos que se deslocaram para o exterior (Estados Unidos e Alemanha) para estudar, oportunidade não verificada nas outras gerações nem mesmo em função do trabalho.

Entre os jovens que tiveram avós, pais ou tios migrantes, a experiência é avaliada positivamente por 39 deles e negativamente por 6 . Aqueles que expressam uma avaliação negativa da trajetória migratória familiar mencionam casos de desemprego, separação de cônjuges e até mesmo assassinato do membro da família no período da migração. Para a avaliação positiva, contribui a possibilidade de compras de terras e/ou investimentos nas melhorias de infraestrutura e nos processos produtivos da propriedade rural. Essas informações permitem confirmar a tese de que a migração para o trabalho era uma estratégia familiar com finalidade de provisionar economicamente a própria reprodução social dos agricultores familiares (ZAGO, 2016). Segundo uma jovem de 25 anos, que tem pai e tios migrantes, "todos melhoraram de vida, adquiriram conhecimento sobre o mundo, fizeram poupança, e reverteram na propriedade rural e no conforto doméstico quando retornaram".

De acordo com os entrevistados, as estratégias migratórias criadas no passado proporcionam, atualmente, um ambiente economicamente favorável ao deslocamento dos jovens para fins de estudo, fator que também fortalece a visão positiva dos benefícios da mobilidade espacial desenvolvida pelos mais velhos. A migração, nesse caso, é 


\section{OREVER}

representada como sucesso e como forma eficiente de se beneficiar das oportunidades disponíveis naquele momento, apesar dos custos pessoais, subjetivos e sociais acarretados pela distância e ausência da convivência familiar. Avalia-se, segundo os participantes da pesquisa, que os jovens do passado concretizaram seus projetos de vida, alcançando autonomia financeira, somando experiências e reformulando suas visões de mundo.

Entre os jovens que atribuem uma valoração positiva à trajetória migratória familiar, 18 afirmaram que o deslocamento para que pudessem cursar a universidade foi diretamente influenciado por esse histórico, dado que, no passado, a busca por emprego nas cidades significava "melhorar de vida" e, atualmente, o ensino superior é o requisito que cumpre esse papel. Os jovens entendem que o prolongamento dos estudos na atualidade é o principal requisito para empregos melhores, pois, nas gerações de pais e avós, "os empregos alcançados nas cidades eram braçais, sem exigências de qualificação profissional", como afirmou um jovem. Outro entrevistado lembrou uma frase incentivadora do pai: "vai e estuda, porque na vida de agricultor não aparecem oportunidades".

O incentivo familiar, além de verbal e financeiro, vem também do próprio resultado positivo das trajetórias passadas, tomadas pelos jovens como exemplo: "Depois que vim embora (para a universidade) comecei a ter mais autonomia, virei adulta, conquistei mais coisas, igual como aconteceu com meus pais"; "Assim como minha família, também saí em busca de novas oportunidades"; "Meu pai migrou, melhorou de vida e conseguiu ajudar o resto da família. Depois da universidade eu também pretendo ajudar meus irmãos mais novos". Tais afirmações permitem perceber a configuração de um imaginário familiar favorável à formação de um capital de mobilidade (BRITO, 2010), guardado na memória e evocado, também, pelas narrativas sobre as migrações que são transmitidas entre as gerações (MENEZES, 2013, COMERFORD, 2014), bem como pelas fotografias, cartas e postais exibidos nas reuniões familiares, como relataram os jovens participantes da pesquisa.

A partir desse mapeamento das trajetórias familiares e da importância da mobilidade espacial para a concretização dos projetos de vida das famílias e dos próprios jovens, procurou-se também identificar, no questionário, quais planos estão sendo elaborados para o futuro. Na definição proposta por Velho (2004), três componentes intervêm na elaboração desses projetos: a) o papel que a memória, individual e coletiva, desempenha, fornecendo o legado de experiências que vai orientar as opções que o indivíduo irá fazer em termos de manutenção ou de mudanças em sua vida futura. É com 


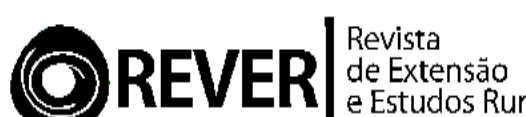

base nessa herança que se planeja os atributos de uma identidade que se quer transformar, projetando-se um vir a ser diferente; b) o potencial de "metamorfose", entendida como a capacidade plástica de mutação, que envolve mudanças de estilo de vida, rompimento de laços sociais antigos e criação de novos vínculos, bem como incorporação de novos papéis sociais e identidades. Esse potencial também revela um aspecto cultural, na medida em que algumas culturas se mostram mais abertas aos contatos interculturais e às heterogeneidades; e c) "campo de possibilidades", isto é, o horizonte da realidade concreta que configura as alternativas disponíveis para ação. Esse repertório é constituído por políticas públicas, condições financeiras e intelectuais do indivíduo, infraestrutura oferecida, trajetória individual até o presente, entre outros fatores. O campo de possibilidades permite avaliar o leque de projetos que são passíveis de formulação em um dado contexto e seu potencial de concretização ou fracasso.

Quanto aos projetos de vida dos participantes da pesquisa, bem como a possibilidade de deslocamento espacial para concretizá-los, o questionário permitia respostas múltiplas e as tabelas abaixo sintetizam algumas dessas projeções.

Tabela 1: Projetos de vida que envolvem deslocamentos para outros lugares

\begin{tabular}{|c|c|c|c|c|c|c|c|c|c|}
\hline Total & \multicolumn{3}{|c|}{ Motivo } & \multicolumn{5}{c|}{ Lugar } \\
\hline \multirow{2}{*}{30} & Trabalho & Estudo & $\begin{array}{c}\text { Outros } \\
\text { (estabilidade } \\
\text { econômica, } \\
\text { qualidade } \\
\text { de vida, } \\
\text { "Goutras } \\
\text { vivências") }\end{array}$ & $\begin{array}{c}\text { Outro } \\
\text { país }\end{array}$ & $\begin{array}{c}\text { Outro } \\
\text { Estado }\end{array}$ & Geral & $\begin{array}{c}\text { Em } \\
\text { Minas } \\
\text { Gerais }\end{array}$ & $\begin{array}{c}\text { Centro } \\
\text { Urbano } \\
\text { (MG e } \\
\text { outros } \\
\text { estados) }\end{array}$ & $\begin{array}{c}\text { Outros } \\
\text { (Qualquer } \\
\text { lugar que } \\
\text { tenha } \\
\text { oportunidade) }\end{array}$ \\
\cline { 2 - 7 } & 21 & 4 & 11 & 3 & 3 & 11 & 9 & 3 & 9 \\
\hline
\end{tabular}

Fonte: Dados da pesquisa, 2017-2018.

Tabela 2: Projetos de vida que não envolvem deslocamentos para outros lugares

\begin{tabular}{|c|c|c|c|c|}
\hline Total & \multicolumn{4}{|c|}{ Motivo } \\
\hline \multirow{2}{*}{11} & Família & Feliz & $\begin{array}{c}\text { Oportunidade } \\
\text { na região }\end{array}$ & $\begin{array}{c}\text { Outros (prefere zona rural, já } \\
\text { migrou, não sabe) }\end{array}$ \\
\cline { 2 - 5 } & 3 & 2 & 2 & 6 \\
\hline
\end{tabular}

Fonte: Dados da pesquisa, 2017-2018.

Os dados da Tabela 1 apontam para projetos futuros diversificados, com 30 jovens declarando diferentes motivações em deslocamentos para obter "empregos melhores", e dentro do campo profissional que envolve o curso universitário no qual estão se 


\section{OREVER/|}

graduando, ou continuar na universidade cursando pós-graduação (no Brasil ou no exterior, citando-se os países onde já se encontram seus irmãos ou primos). Nesse caso, os jovens consideram que o local de oferta de emprego, estudo ou "outras vivências" poderá torná-los "migrantes", já que as condições objetivas para a concretização dos projetos estão situadas geograficamente em outras regiões, dentro ou fora de Minas Gerais ou em outros países.

Em relação àqueles que optaram pelo não deslocamento futuro (Tabela 2), algumas ressalvas devem ser feitas. Nesse grupo, encontram-se não apenas os jovens cujas trajetórias familiares migratórias foram avaliadas como não compensatórias, mas também aqueles que vislumbram um campo de possibilidades quanto à empregabilidade e à obtenção de renda na região (não necessariamente em seus municípios de origem). Convívio familiar e felicidade são critérios mencionados para o deslocamento de retorno, confirmando dados encontrados na bibliografia internacional e nacional, apresentados anteriormente, sobre os compromissos morais de jovens rurais com a família, a propriedade e a localidade.

Alves e Dayrell, ao analisarem projetos de vida de jovens rurais estudantes do ensino médio, residentes em Minas Gerais, em "região marcada pela cultura da migração" (ALVES e DAYRELL, 2015, 375), propõem uma tipologia empregada nesses projetos que, com algumas ressalvas, pode ser utilizada aqui. Os autores indicam que o termo "ser alguém na vida" é o sentido que une todos os projetos, independentemente de suas particularidades. Outrossim, foram identificadas quatro formas de elaboração de projetos: a mimética, que consiste na imitação de alguém, inclusive parentes, que serve de modelo, conquistou determinado status e tem o respeito da sociedade pela posição social ou ocupação profissional; projetos hipomaníacos, que se caracterizam pelo otimismo exacerbado, pelo desconhecimento do campo de possibilidades e por certa fuga da realidade; projetos estratégicos, com conhecimento dos fins e planejamento de etapas e estratégias para alcançá-los, inclusive com a elaboração de um "plano B" para a reorientação da trajetória; projetos de recusa, que negam experiências negativas ou fracassadas, tanto individuais quanto familiares, evitando repetições; além dos jovens fora de projetos que, dadas as várias situações de precariedade, não conseguem antecipar ou vislumbrar um futuro (ALVES e DAYRELL, 2015).

A partir dos dados apresentados nas Tabelas 1 e 2 e das respostas atribuídas às questões abertas do questionário, os jovens rurais universitários participantes da pesquisa formularam projetos de vida que podem ser caracterizados como miméticos, estratégicos 


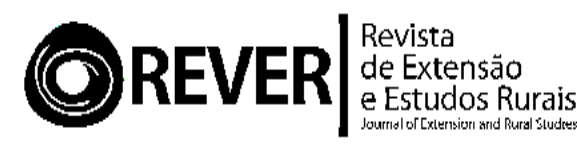

e de recusa. Em primeiro lugar, podemos elencar como projetos miméticos aqueles que incorporam o capital de mobilidade familiar dos jovens que avaliaram positivamente a trajetória migratória de seus parentes. Exemplos são identificados em frases como "assim como meu pai", "assim como minha família", "igual aos meus primos". Contudo, esses projetos não deixam de entrever também uma recusa, ou seja, de negar a reprodução social da profissão de agricultor e as agruras a ela relacionadas. A frase paterna que dá título a esse artigo - "Vai e estuda" - indica claramente o imbricamento dos dois projetos: o ir, valendo-se do legado de experiências migratórias positivas de familiares, e o vir a ser diferente, aproveitando-se de outras oportunidades e campos de possibilidades para "melhorar de vida", para os quais são necessárias estratégias performativas de abertura e adaptação aos diferentes contextos apontados pelos jovens, ou seja, os projetos comportam a metamorfose (VELHO, 2004; DOS ANJOS E CALDAS, 2015).

Da mesma forma, nos projetos nos quais não se antevê a continuidade de deslocamentos, pode-se identificar a recusa de repetir o repertório de fracassos e tragédias de outros familiares, enquanto, por outo lado, transparece o caráter mimético do retorno e do prosseguimento das atividades agrícolas, embora com níveis de conhecimento e profissionalização diferentes. Entre os jovens que avaliaram que as condições de vida de seus parentes pioraram após a migração, todos pretendem voltar para o local de origem após a conclusão do curso universitário, buscando implementar novos conhecimentos técnicos e científicos na gestão da propriedade familiar, visto que declararam que tais estabelecimentos encontram-se improdutivos. É evidente que não se pode, a partir desses casos, estabelecer uma relação direta de causalidade entre trajetórias familiares tidas como fracassadas e o projeto de retorno, mesmo porque esses jovens estão em deslocamento para fins de estudo e, portanto, utilizando o capital de mobilidade de suas famílias. Para esses jovens, principalmente, o projeto futuro reside em dar continuidade à tradição da família agricultora, mas, a exemplo dos entrevistados por Bezerra (2013), a proposta é "ficar e fazer diferente", ou seja, esses jovens se veem como vetores de transformação social.

Tal como ressaltado por Alves e Dayrell (2015), verificou-se, na pesquisa, a reflexividade nos projetos de vida juvenis, que são formulados a partir da avaliação dos resultados das trajetórias familiares no âmbito desses projetos, bem como das experiências vividas no presente por esses jovens, que estão em deslocamento e em contexto universitário. Não se pode deixar de considerar, como ressalta Zago, que a própria experiência da convivência urbana durante a fase dos estudos resulta em "novas 


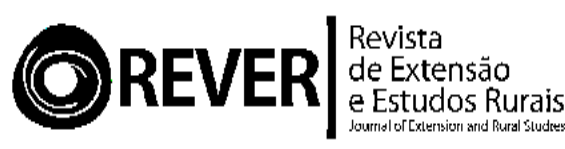

experiências sociais e culturais, podendo ampliar o campo de interesse para outros horizontes de possibilidades" (ZAGO, 2016, p. 76), o que vem sendo reconhecido com positividade pelas famílias, posto que os jovens se apropriam de modelos profissionais mais diversificados e valorizados socialmente.

\section{Considerações finais}

Os resultados da pesquisa apontam para a valorização crescente da educação de nível superior entre famílias e jovens rurais e sua potencialidade para promover a mobilidade social. Essa valorização ocorre em um contexto histórico e social no qual se verifica o aumento da oferta de políticas públicas favoráveis, entre as quais a interiorização dos estabelecimentos de ensino superior. Esse reconhecimento, bem como as oportunidades concretas de acesso, são fatores que modificam as motivações, as temporalidades e as espacialidades das trajetórias migratórias familiares, marcando diferenças geracionais significativas.

A depreciação com que as atividades agrícolas familiares são histórica e socialmente representadas, não só no Brasil, mas em outras partes do mundo, faz com que, na atualidade, parte das famílias não projetem para o futuro a sua reprodução social como agricultoras. Assim, a reprodução social e familiar e a autonomia juvenil implicam avaliar novas possibilidades, não apenas em função das alternativas concretas disponíveis, mas também em função dos capitais familiares (econômicos, culturais e simbólicos) para abraçar certas oportunidades.

No caso desta pesquisa, os dados apontam que as trajetórias juvenis atuais não são dissonantes das trajetórias migratórias familiares do passado, mas sim atualizadas e reinventadas para responder aos novos desafios impostos pelo mercado de trabalho contemporâneo, que não é regional ou nacional, nem rural ou urbano, sendo os trabalhadores selecionados com base em novas habilidades e competências.

Avaliada como estratégia de sucesso, a migração das gerações passadas possibilitou a autonomia e a mobilidade social dos jovens da época, entendidas, naquele contexto, como a possibilidade de pais e avós tornarem-se proprietários e disporem de recursos financeiros para gerir as atividades econômicas a seu modo. Essa trajetória migratória familiar parece ter produzido efeito positivo na atualidade, pois, se nas gerações anteriores os migrantes "melhoraram de vida", os jovens de hoje projetam obter o mesmo sucesso através da educação superior, podendo "tornar-se alguém na vida" em outro lugar. 


\section{OREVER|}

Para finalizar, os dados da pesquisa permitem incorporar aos debates recentes sobre o acesso da juventude rural ao ensino superior a perspectiva familiar e a influência de suas trajetórias migratórias, considerando que, para estudar, obter melhores empregos ou formar um novo repertório de experiências de vida, os jovens têm se deslocado e poderão continuar se deslocando.

Não se pode, porém, dizer que a trajetória migratória familiar, seja ela exitosa seja fracassada, exerce uma pressão determinista, pois o conceito de capital de mobilidade aqui utilizado indica uma predisposição, e não a repetição de um destino com o mesmo percurso, mesmo objetivo e mesmos resultados. Ao contrário, o que se pretende incorporar ao debate é a formulação de estratégias familiares diferenciadas para garantir e investir naquilo que, em determinado contex to de possibilidades, as famílias consideram o melhor para as futuras gerações, visando à autonomia dos jovens como trabalhadores e adultos, e aproveitando as múltiplas oportunidades de mobilidade social.

Destaca-se, finalmente, que os dados da pesquisa não podem ser generalizados, pois se baseiam em apenas um contexto de vivência familiar e juvenil, no qual a ruralidade tem algumas particularidades históricas e culturais e as famílias dispõem de certos capitais. A educação de nível superior ainda está longe de ser uma possibilidade concreta para os jovens rurais em um país com a dimensão territorial do Brasil e, para muitos, o acesso ao ensino superior ainda é um sonho distante.

\section{Referências bibliográficas}

BEZERRA, T. S. Vidas em trânsito: juventude rural e mobilidade(s) pelo acesso ao ensino superior. Dissertação (Mestrado Programa de Pós-Graduação em Sociologia, Departamento de Ciências Sociais). Fortaleza: UFC, 2013.

BOURDIEU, P. A distinção: crítica social do julgamento. São Paulo: Edusp; Porto Alegre: Zouk, 2007.

BOURDIEU, P., MICELI, S. A economia das trocas simbólicas. São Paulo: Perspectiva, 1974.

BRITO, A. X. Habitus de migrante: um conceito que visa captar o cotidiano dos atores em mobilidade espacial. Sociedade e Estado, v. 25, n. 3, p. 431-464, 2010. Disponível em: http://www.scielo.br/scielo.php?pid=S010269922010000300002\&script=sci_arttext\&tlng=pt.

BRITO, F. Brasil, final de século: a transição para um novo padrão migratório? Anais. p.1-44, 2000. Disponível em: http://www.abep.nepo.unicamp.br/docs/anais/pdf/2000/. 


\section{OREVER|}

CARNEIRO, M. J. O ideal rurbano: campo e cidade no imaginário de jovens rurais. In: TEIXEIRA DA SILVA, F. C. et al. (Org.). Mundo rural e política. Rio de Janeiro: Campus, 1999, p.95-117.

CASTRO, E. G. de et al. Os jovens estão indo embora? Juventude rural e a construção de um ator político. Rio de Janeiro: MAUAD X, 2009.

CHIANG, Y.; HANNUM, E.; KAO, G. Who Goes, Who Stays, and Who Studies? Gender, Migration, and Educational Decisions among Rural Youth in China. International Journal of Chinese Education, p.106-131, 2012. Disponível em: http://booksandjournals.brillonline.com/content/journals/10.1163/221258612x644584

COMERFORD, J. Vigiar e narrar: sobre formas de observação, narração e julgamento de movimentações. Revista de antropologia, v. 57, n. 2, p. 107-142, 2014. Disponível em: http://www.revistas.usp.br/ra/article/view/89110

CRIVELLO, G. 'Becoming Somebody': youth transitions through education and migration in Peru'. Young Lives Working Paper, n.43. Department of International Development, University of Oxford, 2009. Disponível em: https://www.younglives.org.uk/sites/www.younglives.org.uk/files/YL-WP43-CrivelloBecomingSomebody.pdf

DE OLIVEIRA, M.; KULAITIS, F. Habitus imigrante e capital de mobilidade: a teoria de Pierre Bourdieu aplicada aos estudos migratórios. Mediações-Revista de Ciências Sociais, v. 22, n. 1, p. 15-47, 2017. Disponível em http://www.uel.br/revistas/uel/index.php/mediacoes/article/view/29616

DE PAULA, M. F. C. Desigualdade e políticas de inclusão na educação superior no Brasil e na Argentina: limites, possibilidades e desafios. RevistAleph, n. 18, 2012. Disponível em: http://www.revistaleph.uff.br/index.php/REVISTALEPH/article/viewFile/32/27

DE PAULO, M. A. L.; DE OLIVEIRA SILVA, C. N. Juventude rural e ensino superior: acesso, limites, possibilidades e transformações. In: XXIX Congresso Latino-americano de Sociologia, 2013, Santiago - Chile. XXIX Congresso Latino-americano de Sociologia, 2013.

Disponível

em: http://actacientifica.servicioit.cl/biblioteca/gt/GT22/GT22_LimadePaulo_NatanaeldeOli veira.pdf

DOS ANJOS, Flávio Sacco; CALDAS, Nádia Velleda. Ser ou não ser agricultor? Eis a questão. Representações sociais sobre a profissão de agricultor entre jovens de comunidade rural do Sul do Brasil.. Revista de Extensão e Estudos Rurais, Viçosa, MG, v. 4, n. 1, out. 2015. ISSN 2359-5116. Disponível em: <https://periodicos.ufv.br/ojs/rever/article/view/3303/1572>. Acesso em: 03 jul. 2019. doi:https://doi.org/10.18540/rever412015\%p.

GARCIA, R. A.; DE MIRANDA-RIBEIRO, A. Movimentos migratórios em Minas Gerais: efeitos diretos e indiretos da migração de retorno-1970-1980, 1981-1991 e 19902000. Revista Brasileira de Estudos de População, v. 22, n. 1, p. 159-175, 2013. Disponível em: https://rebep.org.br/revista/article/view/262/pdf_243 


\section{OREVER|}

INEP. (Instituto Nacional de Estudos e Pesquisas Educacionais Anísio Teixeira). Sinopse Estatística da Educação Superior 2001. Brasília: INEP, 2002. Disponível em: http://portal.inep.gov.br/web/guest/sinopses-estatisticas-da-educacao-superior

INEP. Instituto Nacional de Estudos e Pesquisas Educacionais Anísio Teixeira. Sinopse Estatística da Educação Superior 2016. Brasília: INEP, 2017. Disponível em: http://portal.inep.gov.br/web/guest/sinopses-estatisticas-da-educacao-superior

IRVIN, M. J. et al. Educational barriers of rural youth: Relation of individual and contextual difference variables. Journal of Career Assessment, v.20, n.1, p.71-87, 2012. Disponívelem:

http://citeseerx.ist.psu.edu/viewdoc/download?doi=10.1.1.926.8052\&rep=rep1\&type=p $\underline{\mathrm{df}}$

LEAVY, J.; SMITH, S. Future Farmers: Youth Aspirations, Expectations and Life Choices.Future Agricultures Discussion Paper, n.13. Brighton: Institute of Development Studies, $2010 . \quad$ Disponível em: http://citeseerx.ist.psu.edu/viewdoc/download?doi=10.1.1.360.7495\&rep=rep1\&type $=p$ $\underline{\mathrm{df}}$

MENEZES, M. A. Família, juventude e migrações. Revista Anthropológicas, v. 23, n. 1, 2012.

Disponível

em: https://periodicos.ufpe.br/revistas/revistaanthropologicas/article/download/23747/19393

PAULO, M. A. L. Juventude rural: suas construções identitárias. Recife, PE: Editora Universitária UFPE, 2011.

RIBEIRO, M. G. M. Caubóis e Caipiras. Os Land Grant Colleges e a Escola Superior de Agricultura de Viçosa. RevistaHistória da Educação, v. 10, n. 19, 2006.

RYE, J. F. Youth migration, rurality and class: a Bourdieusian approach. EuropeanUrban and Regional Studies, v. 18, n. 2, p. 170-183, 2011. Disponível em: https://core.ac.uk/download/pdf/154670080.pdf

STROPASOLAS, V. L. A dimensão da diversidade social na concepção de políticas públicas para a juventude rural. In: MENEZES, M. A.; STROPASOLAS, V. L.; BARCELOS, S. B. Juventude rural e políticas públicas no Brasil. Brasília: Nead/MDA, p.178-199, 2014.

VELHO, Gilberto. Individualismo e cultura. Rio de Janeiro: Jorge Zahar Editores, 2004.

ZAGO, N. Migração rural-urbana, juventude e ensino superior. Rev. Bras. Educ., v. 21, n. 64, p. 61-78. Rio de Janeiro, 2016. Disponível em: http://www.scielo.br/scielo.php?script=sci_arttext\&pid=S141324782016000100061\&lng=pt\&nrm=iso 